\title{
Small whole heart volume predicts cardiovascular events in patients with stable chest pain: insights from the PROMISE trial
}

Citation for published version (APA):

Foldyna, B., Zeleznik, R., Eslami, P., Mayrhofer, T., Scholtz, J. E., Ferencik, M., Bittner, D. O.,

Meyersohn, N. M., Puchner, S. B., Emami, H., Pellikka, P. A., Aerts, H. J. W. L., Douglas, P. S., Lu, M. T., \& Hoffmann, U. (2021). Small whole heart volume predicts cardiovascular events in patients with stable chest pain: insights from the PROMISE trial. European Radiology, 31(8), 6200-6210.

https://doi.org/10.1007/s00330-021-07695-2

Document status and date:

Published: 01/08/2021

DOI:

10.1007/s00330-021-07695-2

Document Version:

Publisher's PDF, also known as Version of record

Document license:

Taverne

Please check the document version of this publication:

- A submitted manuscript is the version of the article upon submission and before peer-review. There can be important differences between the submitted version and the official published version of record.

People interested in the research are advised to contact the author for the final version of the publication, or visit the DOI to the publisher's website.

- The final author version and the galley proof are versions of the publication after peer review.

- The final published version features the final layout of the paper including the volume, issue and page numbers.

Link to publication

\footnotetext{
General rights rights.

- You may freely distribute the URL identifying the publication in the public portal. please follow below link for the End User Agreement:

www.umlib.nl/taverne-license

Take down policy

If you believe that this document breaches copyright please contact us at:

repository@maastrichtuniversity.nl

providing details and we will investigate your claim.
}

Copyright and moral rights for the publications made accessible in the public portal are retained by the authors and/or other copyright owners and it is a condition of accessing publications that users recognise and abide by the legal requirements associated with these

- Users may download and print one copy of any publication from the public portal for the purpose of private study or research.

- You may not further distribute the material or use it for any profit-making activity or commercial gain

If the publication is distributed under the terms of Article $25 \mathrm{fa}$ of the Dutch Copyright Act, indicated by the "Taverne" license above, 


\title{
Small whole heart volume predicts cardiovascular events in patients with stable chest pain: insights from the PROMISE trial
}

\author{
Borek Foldyna ${ }^{1,2}(1) \cdot$ Roman Zeleznik $^{3,4} \cdot$ Parastou Eslami $^{1} \cdot$ Thomas Mayrhofer $^{1,5} \cdot$ Jan-Erik Scholtz ${ }^{1,6}$. \\ Maros Ferencik $^{1,7} \cdot$ Daniel O. Bittner ${ }^{1,8} \cdot$ Nandini M. Meyersohn $^{1}$. Stefan B. Puchner ${ }^{1,9} \cdot$ Hamed Emami $^{1}$. \\ Patricia A. Pellikka ${ }^{10} \cdot$ Hugo J. W. L. Aerts ${ }^{1,3,4,11} \cdot$ Pamela S. Douglas ${ }^{12} \cdot$ Michael T. Lu $^{1} \cdot$ Udo Hoffmann $^{1}$
}

Received: 13 October 2020 / Revised: 4 December 2020 / Accepted: 18 January 2021 / Published online: 26 January 2021

(C) European Society of Radiology 2021

\begin{abstract}
Objectives The size of the heart may predict major cardiovascular events (MACE) in patients with stable chest pain. We aimed to evaluate the prognostic value of 3D whole heart volume (WHV) derived from non-contrast cardiac computed tomography (CT). Methods Among participants randomized to the CT arm of the Prospective Multicenter Imaging Study for Evaluation of Chest Pain (PROMISE), we used deep learning to extract WHV, defined as the volume of the pericardial sac. We compared the WHV across categories of cardiovascular risk factors and coronary artery disease (CAD) characteristics and determined the association of WHV with MACE (all-cause death, myocardial infarction, unstable angina; median follow-up: 26 months).

Results In the 3798 included patients $\left(60.5 \pm 8.2\right.$ years; $51.5 \%$ women), the WHV was $351.9 \pm 57.6 \mathrm{~cm}^{3} / \mathrm{m}^{2}$. We found smaller WHV in no- or non-obstructive CAD, women, people with diabetes, sedentary lifestyle, and metabolic syndrome. Larger WHV was found in obstructive CAD, men, and increased atherosclerosis cardiovascular disease (ASCVD) risk score $(p<0.05)$. In a time-to-event analysis, small WHV was associated with over 4.4-fold risk of MACE (HR (per one standard deviation) = 0.221; 95\% CI: $0.068-0.721 ; p=0.012$ ) independent of ASCVD risk score and CT-derived CAD characteristics. In patients with nonobstructive CAD, but not in those with no- or obstructive CAD, WHV increased the discriminatory capacity of ASCVD and CTderived CAD characteristics significantly.

Conclusions Small WHV may represent a novel imaging marker of MACE in stable chest pain. In particular, WHV may improve risk stratification in patients with non-obstructive CAD, a cohort with an unmet need for better risk stratification.

Key Points

- Heart volume is easily assessable from non-contrast cardiac computed tomography.

- Small heart volume may be an imaging marker of major adverse cardiac events independent and incremental to traditional cardiovascular risk factors and established CT measures of CAD.

- Heart volume may improve cardiovascular risk stratification in patients with non-obstructive CAD.
\end{abstract}

Borek Foldyna

bfoldyna@mgh.harvard.edu

1 Cardiovascular Imaging Research Center, Massachusetts General Hospital - Harvard Medical School, 165 Cambridge Street, Suite 400, Boston, MA 02114, USA

2 Department of Radiology, Rhön Klinikum - Campus Bad Neustadt, Bad Neustadt an der Saale, Germany

3 Artificial Intelligence in Medicine (AIM) Program, Brigham and Women's Hospital - Harvard Medical School, Boston, MA, USA

4 Department of Radiation Oncology, Brigham and Women's Hospital, Dana-Farber Cancer Institute, Harvard Medical School, Boston, MA, USA

5 School of Business Studies, Stralsund University of Applied Sciences, Stralsund, Germany
6 Department of Diagnostic and Interventional Radiology, University Hospital Frankfurt, Frankfurt am Main, Germany

7 Knight Cardiovascular Institute, Oregon Health \& Science University, Portland, OR, USA

8 Department of Cardiology, Friedrich-Alexander University Erlangen-Neurnberg (FAU), University Hospital Erlangen, Erlangen, Germany

9 SBP Department of Biomedical Imaging and Image-Guided Therapy, Medical University of Vienna, Vienna, Austria

10 Department of Cardiovascular Medicine, Mayo Clinic, Rochester, MN, USA

11 Department of Radiology and Nuclear Medicine, Maastricht University Medical Center+, Maastricht, The Netherlands

12 Duke Clinical Research Institute, Duke University School of Medicine, Durham, NC, USA 
Keywords Multidetector computed tomography $\cdot$ Cardiac volume $\cdot$ Heart failure $\cdot$ Coronary disease

$\begin{array}{ll}\text { Abbreviations } \\ \text { ASCVD } & \text { Atherosclerosis cardiovascular disease } \\ \text { AUC } & \text { Area under the curve } \\ \text { BSA } & \text { Body surface area } \\ \text { CAC } & \text { Coronary artery calcium } \\ \text { CAD } & \text { Coronary artery disease } \\ \text { CI } & \text { Confidence interval } \\ \text { CT } & \text { Computed tomography } \\ \text { CTA } & \text { Computed tomography angiography } \\ \text { CV } & \text { Cardiovascular } \\ \text { DL } & \text { Deep learning } \\ \text { HR } & \text { Hazard ratio } \\ \text { HRPF } & \text { High-risk plaque features } \\ \text { IQR } & \text { Interquartile range } \\ \text { MACE } & \text { Major adverse cardiac events } \\ \text { MI } & \text { Myocardial infarction } \\ \text { ROC } & \text { Receiver operator characteristic } \\ \text { SD } & \text { Standard deviation } \\ \text { UA } & \text { Unstable angina } \\ \text { WHV } & \text { Whole heart volume }\end{array}$

\section{Introduction}

Cardiac computed tomography (CT) is increasingly used to exclude obstructive coronary artery disease in patients presenting with stable chest pain. According to the most recent European Society of Cardiology Guidelines, cardiac CT represents a first-line diagnostic method to assess cardiovascular (CV) risk in patients with chronic coronary syndromes, including those with stable chest pain [1]. While cardiac CT is a reliable method to exclude coronary artery disease (CAD) (negative predictive value $\sim 99 \%$ ) and to detect obstructive $\mathrm{CAD}$, assessment of $\mathrm{CV}$ risk remains challenging, especially in those with non-obstructive disease [2]. Symptomatic patients with non-obstructive CAD, however, account for the majority of future $\mathrm{CV}$ events [3, 4], require advanced risk stratification, and are frequently referred to further testing.

CT-derived measures beyond stenosis assessment have revealed an additional prognostic value. For instance, elevated coronary artery calcium (CAC) or presence of high-risk plaque features (HRPF) on CT angiograms have been associated with increased risk of major adverse $\mathrm{CV}$ events (MACE) $[3,5,6]$. In addition to showing coronary arteries, cardiac CT has an advantage to image adjacent anatomical structures. Advanced CAD phenotyping, incorporating these structures, may leverage additional information and improve risk stratification. For example, epicardial adipose tissue, size of individual cardiac chambers, or CT-derived cardiac function has been related to adverse $\mathrm{CV}$ events beyond coronary stenosis and clinical risk factors [7-10].

Regarding heart morphology, the diameter of the heart on $\mathrm{X}$-ray, and its proportion to thorax size (i.e., cardiothoracic ratio), is established measures of CV risk [11-14]. However, the prognostic value of CT-derived whole heart volume (WHV), a detailed 3D measure of heart size available in all cardiac CT scans, has not been evaluated yet. Thus, this study's primary aim was to determine the association of WHV with MACE, adjusting for traditional measures of CV risk (i.e., atherosclerotic cardiovascular disease [ASCVD] risk score) and CAD characteristics on CT. In a final step, we performed a subgroup analysis across $\mathrm{CAD}$ categories (i.e., no-, non-obstructive, and obstructive $\mathrm{CAD}$ ) and determined whether WHV had discriminatory capacity incremental to ASCVD risk score and CT-derived CAD characteristics.

\section{Methods}

\section{Study population and clinical characteristics}

In this sub-study of the Prospective Multicenter Imaging Study for Evaluation of Chest Pain (PROMISE) trial, we included patients who were randomized to anatomical testing and received non-contrast cardiac $\mathrm{CT}$ and contrast-enhanced coronary CT angiography (CTA). As per the PROMISE trial inclusion criteria, patients with known $\mathrm{CAD}$ or heart failure were not included. We excluded patients who received the first test other than CTA, did not undergo testing, received non-contrast CT only, or those with unavailable or nondiagnostic image data (Consort diagram Fig.1). Demographics and traditional $\mathrm{CV}$ risk factors were assessed with standard methods at the time of enrollment to the PROMISE trial [15]. Local and central institutional review boards approved the study, and all patients provided written informed consent.

\section{Follow-up and the endpoints}

All patients were followed for a median of 2 years. The primary endpoint was MACE, defined as a composite of allcause mortality $(\mathrm{CV}+$ non- $\mathrm{CV}$ death), non-fatal myocardial infarction (MI), and hospitalization for unstable angina (UA), as adjudicated by an independent committee [15].

\section{WHV-definition and measurements}

WHV $\left(\mathrm{cm}^{3}\right)$ was defined as the volume of the pericardial sac, including all chambers (i.e., ventricles and atria), walls, and 


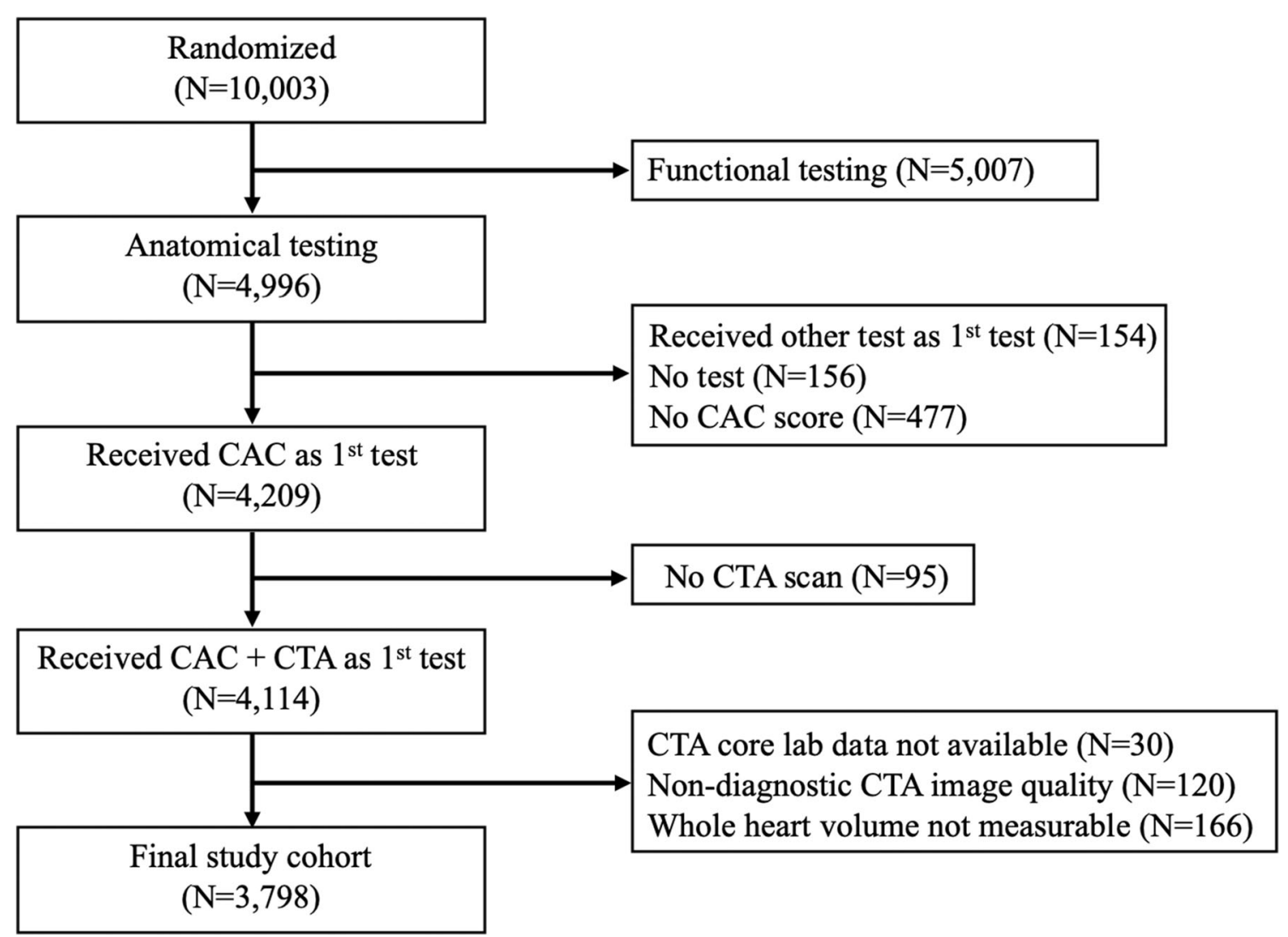

Fig. 1 Consort diagram. $C A C$, coronary artery calcium; $C T A$, computed tomography angiography

coronary arteries, but excluding epicardial fat (tissue $\leq-45$ $\mathrm{HU})$. The cranial border was the axial slice at the level of the right mid pulmonary artery (Fig. 2). To adjust for individual body size differences, we indexed the WHV by body surface area (BSA) $\left(\mathrm{cm}^{3} / \mathrm{m}^{2}\right)[16]$.

To decrease segmentation time, increase clinical feasibility, and standardize the measurement of WHV, we used a deep learning system for the segmentation. The system consisted of two consecutive deep learning networks of the U-Net architecture, to (1) localize and (2) segment the heart. The code was written in Python (v2.7) [17] using Tensorflow-GPU (v1.14) [18], Keras (v2.3.1) [19] with NVIDIA CUDA (v10.2) [20].

To ensure generalizability of the system, the training and tuning cohorts included 858 multicenter and multi-vendor CT scans from the Framingham Heart Study (FHS $n=628$ ), the Prospective Multicenter Imaging Study for Evaluation of Chest Pain (PROMISE, $n=130$ ), and the National Lung Screening Trial (NLST, $n=100$ ). Three experienced readers (B.F., P.E., J.E.S.) provided manually segmented hearts for the training (i.e., supervised learning). Here, the readers traced pericardial contours in axial images at $15-\mathrm{mm}$ intervals and interpolated the space between the images using 3D Slicer (v.4.10) [21].

To further increase the segmentation accuracy, we automatically removed possibly incorrectly segmented lung tissue by excluding outer voxels with an attenuation $<-400 \mathrm{HU}$.
There was no manual correction of the automatic segmentations. The system accuracy was determined on an independent external validation dataset of 1010 manually segmented hearts in PROMISE, revealing an excellent agreement (Dice coefficient: $0.94 \pm 0.02$ ).

\section{CT-derived CAD characteristics}

Experienced core lab readers measured $\mathrm{CAC}$ on non-contrast cardiac CT using the standard Agatston method [22]. Moreover, our core lab assessed all coronary arteries for the presence of CAD (non-obstructive: 1-69\% and obstructive $\geq 70 \%$ maximal luminal narrowing in any coronary artery or $\geq 50 \%$ in the left main coronary artery) as well as the presence of HRPF as described elsewhere [5]. To determine CAD extent, accounting for plaque location and morphology, we calculated the Leaman score, an established tool to quantify total coronary atherosclerotic burden with information regarding localization, type of plaque, and degree of stenosis [23].

\section{Statistical analysis}

Continuous variables were expressed as mean \pm standard deviation (SD) or median (interquartile range (IQR)) and categorical variables as frequencies and percentages. Differences of WHV across clinical characteristics were tested with the 


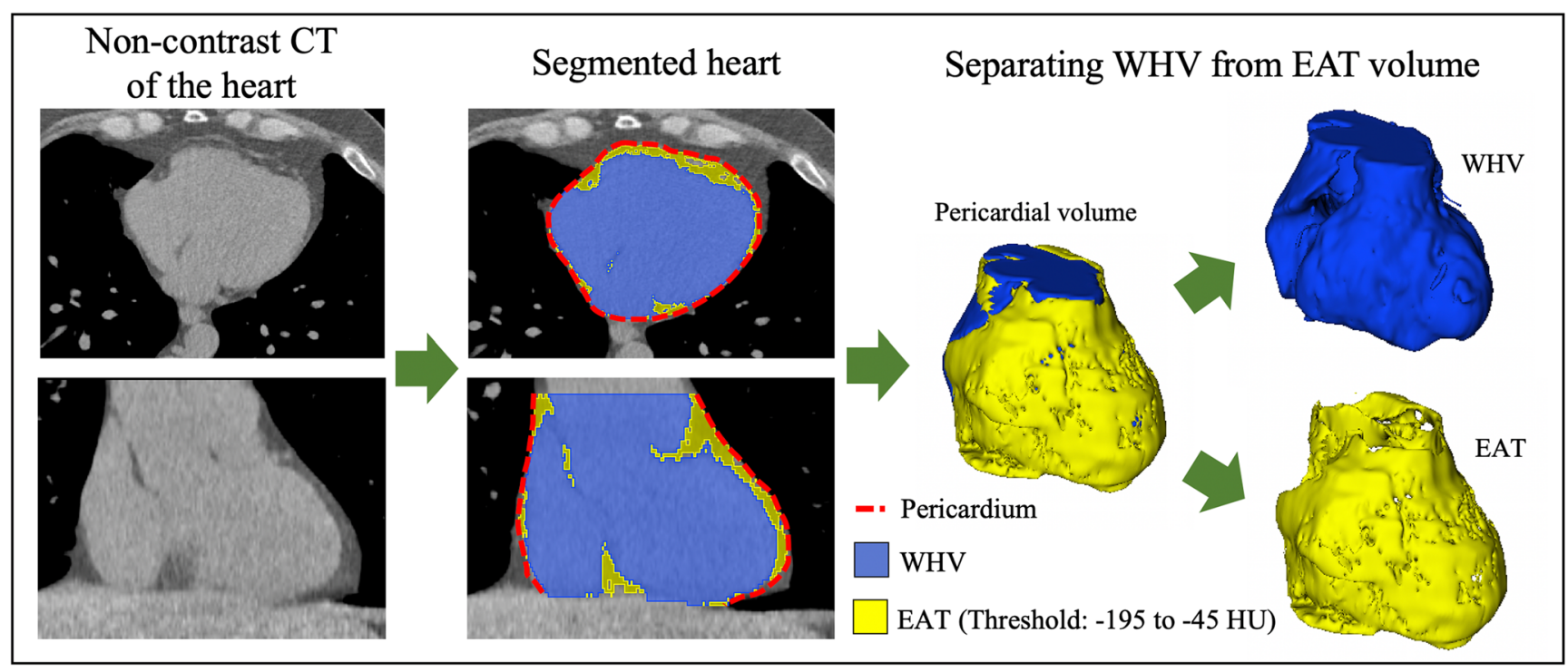

Fig. 2 Measurements of WHV on non-contrast CT. Segmented hearts were derived from non-contrast cardiac $\mathrm{CT}$ images. The natural border was the pericardial sac (red-dotted line), and the segmentation ranged from the mid-right pulmonary artery (PA) to the most caudal part of the

Wilcoxon rank-sum test, while differences between categorical variables were tested with Fisher's exact test.

Univariate and multivariate Cox regressions were used to estimate the association of WHV with MACE. Results were reported as hazard ratios (HR) and 95\% confidence intervals (CI). All regressions were stepwise adjusted for age, sex, ASCVD risk score, and Leaman score. Standard KaplanMeier survival curves incl. log-rank tests showed the differences in event-free survival across quintiles of WHV.

To test the incremental value of WHV, we evaluated whether the model fit increases significantly by adding WHV to the ASCVD risk and Leaman scores using the likelihood-ratio test for nested models. We also calculated receiver operator characteristic (ROC) curves to determine the area under the curve (AUC) and estimate the increase of discriminatory capacity.

All analyses were performed in Stata 15.0, and two-sided $p$ values $<0.05$ were considered statistically significant.

\section{Results}

\section{Study population}

Out of the 4996 PROMISE patients randomized to anatomical testing, 3798 fulfilled the inclusion criteria (Fig. 1). The analytic cohort consisted of middle-aged ( $60.5 \pm 8.2$ years), mostly overweight (median BMI: $30.3 \pm 5.8 \mathrm{~kg} / \mathrm{m}^{2}$ ), and predominantly male patients $(58.5 \%$ ) with intermediate $\mathrm{CV}$ risk (mean 10 year ASCVD risk score: $14.3 \pm 11.4 \%$ ) (Table 1). On coronary CTA, the mean Leaman score was $5.0 \pm 5.1$, and HRPFs were pericardial sac. To render WHV (blue), we subtracted the EAT volume (yellow), defined as fatty tissue with density thresholds of - 195 to - 45 HU. $C T$, computed tomography; EAT, epicardial adipose tissue; $H U$, Hounsfield units; $W H V$, whole heart volume

present in 582/3798 (15.3\%) patients. Over a median follow-up of 26.1 (18.0-34.4) months, 116/3,798 (3.1\%) patients experienced MACE (MI: 21/116 (18.1\%); death: 53/116 (45.7\%); CV death: 30/116 (25.9\%); UA: 46/116 (39.7\%)).

\section{Differences of WHV across categories of CV risk factors and CAD characteristics}

The mean WHV was $351.9 \pm 57.6 \mathrm{~cm}^{3} / \mathrm{m}^{2}$ (range 100.6 $746.1 \mathrm{~cm}^{3} / \mathrm{m}^{2}$ ). In general, men and those with increased ASCVD risk $(\geq 7.5 \%)$ and advanced CAD (i.e., obstructive $\mathrm{CAD}$, higher CAC score, HRPF present) presented with larger hearts ( $p<0.001$ for all). On the other hand, women, patients with no- or non-obstructive CAD, obese patients, and those with metabolic syndrome, and sedentary lifestyle presented with significantly smaller hearts ( $p<0.05$ for all). Separated by median age (59.7 years), WHV did not differ between younger and older patients $(p=0.397)$. Individual WHV across categories of $\mathrm{CV}$ risk factors and $\mathrm{CAD}$ characteristics on $\mathrm{CT}$ are shown in Fig. 3.

\section{Association of WHV with MACE}

Patients who experienced MACE had smaller WHV compared to those without MACE $(346.0 \pm 55.4$ vs. $352.1 \pm$ $\left.57.6 \mathrm{~cm}^{3} / \mathrm{m}^{2} ; p=0.005\right)$. In an age- and sex-adjusted timeto-event analysis, we found that a decrease of WHV by one standard deviation was associated with over 4.4 times higher hazard of MACE (HR (per one standard deviation increase $)=$ $0.225,95 \%$ CI: $0.066-0.769, p=0.017)$. This association remained significant and at a similar magnitude after adjusting 
Table 1 Baseline characteristics

\begin{tabular}{|c|c|c|c|c|}
\hline Mean $\pm \mathrm{SD}$ or $n(\%)$ & All $(N=3798)$ & No MACE $(N=3682)$ & $\operatorname{MACE}(N=116)$ & $p$ \\
\hline \multicolumn{5}{|l|}{ Demographics } \\
\hline Age, years & $60.5 \pm 8.2$ & $60.4 \pm 8.2$ & $63.0 \pm 9.1$ & 0.003 \\
\hline Women & $1955(51.5)$ & $1905(51.7)$ & $50(43.1)$ & 0.073 \\
\hline \multicolumn{5}{|l|}{ Cardiovascular risk factors } \\
\hline Hypertension & $2441(64.3)$ & $2361(64.1)$ & $80(69.0)$ & 0.325 \\
\hline Diabetes mellitus & $773(20.4)$ & $744(20.1)$ & $29(25.0)$ & 0.200 \\
\hline Dyslipidemia & $2562(67.5)$ & $2486(67.5)$ & $76(65.5)$ & 0.687 \\
\hline BMI, $\mathrm{kg} / \mathrm{m}^{2}$ & $30.3 \pm 5.8$ & $30.3 \pm 5.8$ & $29.7 \pm 5.7$ & 0.255 \\
\hline Current or past smoker & $1954(51.5)$ & $1878(51.0)$ & $76(65.5)$ & 0.002 \\
\hline Family history of premature $(<55$ years $)$ CAD & $1258(33.2)$ & $1222(33.3)$ & $36(31.0)$ & 0.689 \\
\hline Any PAD & $193(5.1)$ & $185(5.0)$ & $8(6.9)$ & 0.385 \\
\hline Metabolic syndrome & $1379(36.3)$ & $1334(36.2)$ & $45(38.8)$ & 0.624 \\
\hline Sedentary lifestyle & $1819(48.0)$ & $1747(47.5)$ & $72(62.1)$ & 0.002 \\
\hline \multicolumn{5}{|l|}{ Cardiovascular risk, $\%$} \\
\hline ASCVD risk score & $14.3 \pm 11.4$ & $14.2 \pm 11.3$ & $20.2 \pm 13.7$ & $<0.001$ \\
\hline \multicolumn{5}{|l|}{ Relevant medication } \\
\hline Beta-blocker & $904(24.8)$ & $878(24.8)$ & $31(27.4)$ & 0.508 \\
\hline ACE inhibitor or ARB & $1579(43.4)$ & $1529(43.4)$ & $50(44.3)$ & 0.848 \\
\hline Statin & $1659(45.6)$ & $1611(45.7)$ & $48(42.5)$ & 0.565 \\
\hline Aspirin & $1639(45.0)$ & $1589(45.1)$ & $50(44.3)$ & 0.924 \\
\hline Left ventricular EF*, \% & $64.6 \pm 9.0$ & $64.6 \pm 8.9$ & $65.2 \pm 10.8$ & 0.648 \\
\hline \multicolumn{5}{|l|}{$\mathrm{CAD}$ on cardiac $\mathrm{CT}$} \\
\hline Coronary calcium score & $20.2(0.0-159.3)$ & $18.2(0.0-150.2)$ & $146.4(19.6-405.0)$ & $<0.001$ \\
\hline Leaman score & $3.7(0.0-8.6)$ & $3.7(0.0-8.4)$ & $8.0(4.6-13.1)$ & $<0.001$ \\
\hline No CAD & $1297(34.2)$ & $1286(34.9)$ & $11(9.5)$ & $<0.001$ \\
\hline Non-obstructive CAD (1-69\%) & $2268(59.7)$ & $2192(59.5)$ & $76(65.5)$ & \\
\hline Obstructive CAD ( $\geq 70 \%)$ & $233(6.1)$ & $204(5.5)$ & $29(25.0)$ & \\
\hline
\end{tabular}

$A C E$, angiotensin-converting enzyme; $A R B$, angiotensin receptor blocker; $A S C V D$, atherosclerotic cardiovascular disease; $B M I$, body mass index; $C A D$, coronary artery disease; $C T$, computed tomography; $M A C E$, major adverse cardiac events; $P A D$, peripheral arterial disease. *Available in a subgroup of 1815 patients. Values expressed as mean $\pm \mathrm{SD}$, median (IQR) or $N(\%)$

for the clinical ASCVD risk and Leaman score (adjusted HR = $0.221,95 \%$ CI: $0.068-0.721, p=0.012$ ). Additional results for raw WHV (i.e., not BSA-indexed) revealed similar results and are shown in Table 2. In a supplemental analysis, WHV remained significantly associated with MACE in a combined model adjusting for ASCVD, Leaman score, and CAC (BSAindexed and $\ln$-transformed WHV: $\mathrm{HR}=0.21,95 \% \mathrm{CI}$ : $0.066-0.710, p=0.011)$.

\section{WHV across subgroups of CAD}

On coronary CTA, 1297 (34.2\%), 2268 (59.7\%), and 233 $(6.1 \%)$ patients presented with no-, non-obstructive, and obstructive CAD, respectively. Event rates differed significantly between patients without CAD and those with nonobstructive and obstructive disease $(0.9 \%$ vs. $3.4 \%$ vs. $12.5 \%$, respectively; log-rank test, $p<0.001)$. In patients with non-obstructive CAD, a decrease in WHV by one standard deviation was associated with 16.7 times higher hazard of MACE independent of ASCVD risk and Leaman score (adjusted HR $=0.06,95 \%$ CI: 0.013-0.269, $p<0.001$ ). However, there was no significant association between WHV and MACE in those with no- or obstructive CAD ( $p$ $=0.146-0.853$ ). Table 3 provides the results for raw WHV and BSA-adjusted WHV, which have shown similar results as the standardized WHV.

\section{Non-obstructive CAD and WHV}

In our cohort, the majority ( $n=76 / 116 ; 66 \%$ ) of incident events occurred in the 2268 patients with non-obstructive CAD. Among these, women presented with a slightly higher event rate compared to men (3.7\% vs. $3.1 \%)$. Across quintiles of WHV, the MACE rate ranged between 2.3 and $5.4 \%$, being nearly twice as high in the lowest quintile of WHV compared to Q2-5 (5.4\% vs. 2.3-3.3\%). In a time-to-event analysis, the 
Fig. 3 Whole heart volume, cardiovascular risk factors, and CAD on CT. Red-dotted line marks the mean WHV as reference $\left(351.9 \mathrm{~cm}^{3} / \mathrm{m}^{2}\right)$. Bracketed lines represent standard deviations. ASCVD, atherosclerotic cardiovascular disease; CAC, coronary artery calcium; CAD, coronary artery disease; EF, ejection fraction; HRPF, high-risk plaque features; HTN, arterial hypertension; WHV, whole heart volume; $\mathrm{PAD}$, peripheral arterial disease

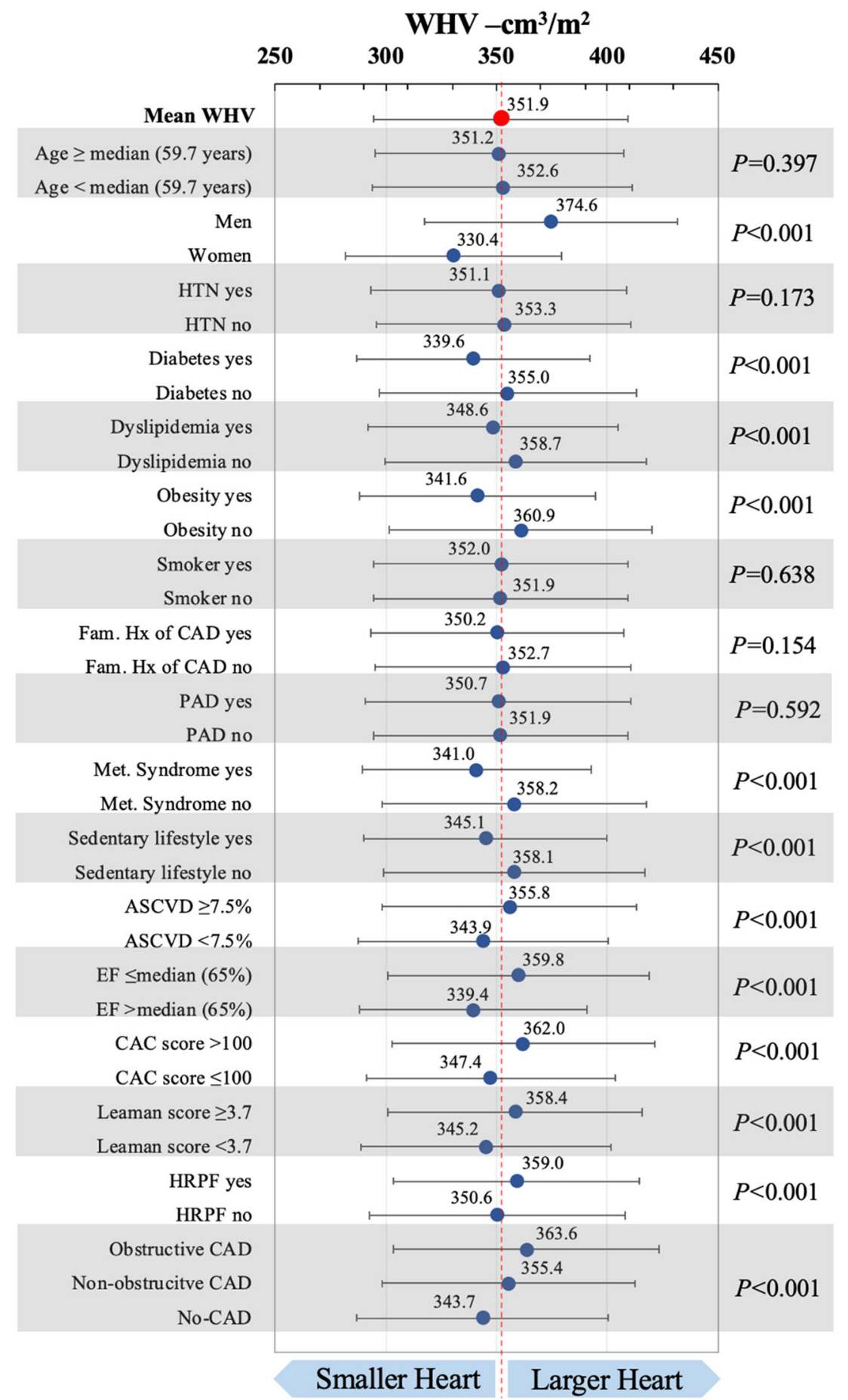

WHV $-\mathbf{c m}^{3} / \mathbf{m}^{2}$

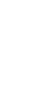


Table 2 Association of WHV with MACE in all patients with stable chest pain $(N=3798$; MACE: $N=116)$

\begin{tabular}{|c|c|c|c|c|c|c|}
\hline & \multicolumn{3}{|c|}{ Adjusted for age and sex } & \multicolumn{3}{|c|}{ Adjusted for ASCVD and Leaman score } \\
\hline & HR & $95 \% \mathrm{CI}$ & $p$ & HR & $95 \% \mathrm{CI}$ & $p$ \\
\hline WHV (absolute), $\mathrm{mm}^{3}$ & 0.998 & $0.997-1.000$ & 0.035 & 0.999 & $0.997-1.000$ & 0.024 \\
\hline WHV (BSA-indexed), $\mathrm{cm}^{3} / \mathrm{m}^{2}$ & 0.996 & $0.992-0.999$ & 0.022 & 0.996 & $0.992-0.999$ & 0.018 \\
\hline WHV (BSA-indexed + ln-transformed) & 0.225 & $0.066-0.769$ & 0.017 & 0.221 & $0.068-0.721$ & 0.012 \\
\hline
\end{tabular}

Association of WHV with MACE (death, MI, or hospitalization for unstable angina). ASCVD, atherosclerotic cardiovascular disease; BSA, body surface area; $M A C E$, major adverse cardiac events; $W H V$, whole heart volume

\section{Incremental value of WHV in non-obstructive CAD}

In patients with stable chest pain and non-obstructive CAD, clinical parameters (i.e., ASCVD risk score), the CT-derived Leaman score, and WHV reached only a fair discriminatory capacity (AUC $=0.627,0.599$, and 0.589 , respectively). While adding Leaman score to the ASCVD risk score did not lead to relevant changes of the AUC (0.627 vs. 0.627), the addition of WHV to the model resulted in a statistically significant improvement of model fit (likelihood-ratio test (3 degrees of freedom): $\left.X^{2}=17.9 ; p<0.001\right)$. Correspondingly, the AUC increased by $4.6 \%$ reaching an AUC of 0.673 (Fig. 6). We did not test for incremental value of WHV in patients with no- or obstructive $\mathrm{CAD}$, since the initial tests (i.e., regressions) were negative.

\section{Discussion}

The primary finding of this study is that small WHV is an independent prognostic imaging marker of MACE among stable chest pain patients. This association is the strongest in those with non-obstructive CAD, a group of patients with the highest need for enhanced risk stratification. Moreover, in this group, WHV improves the discriminatory capacity of the traditional clinical $\mathrm{CV}$ risk factors and CTA-derived CAD characteristics.

\section{Small hearts and MACE}

Because our finding of an association of small WHV with MACE, especially in those with non-obstructive CAD, was independent of traditional CV risk factors and CAD burden, and that patients with small WHV experienced predominantly unspecific events, we suggest that the mechanism relating small WHV with MACE may not be directly linked to epicardial coronary atherosclerosis.

A clue, elucidating the potential pathophysiological/ mechanistic link between small WHV and MACE, may be found in that small WHV was more frequent in women, people with diabetes, obese patients with metabolic syndrome, and sedentary lifestyle. This constellation, especially in the presence of non-obstructive $\mathrm{CAD}$, has been described in the early stages of heart failure with preserved ejection fraction (HFpEF) [24-26]. Here, despite normal cardiac function, a combination of cardiometabolic disorder and nonobstructive CAD promotes myocardial fibrosis with concentric LV-remodeling [27, 28] and ultimately increased risk for

Table 3 Association of WHV with MACE stratified by CAD status on CTA

\begin{tabular}{|c|c|c|c|c|c|c|}
\hline \multirow[t]{2}{*}{ Adjustment } & \multicolumn{3}{|c|}{ Age and sex } & \multicolumn{3}{|c|}{ ASCVD and Leaman score } \\
\hline & HR & $95 \% \mathrm{CI}$ & $P$ & HR & $95 \% \mathrm{CI}$ & $P$ \\
\hline \multicolumn{7}{|c|}{ No CAD: $0 \%$ stenosis $(N=1297$; MACE: $N=11)$} \\
\hline WHV (absolute) $\mathrm{cm}^{3}$ & 1.002 & $0.998-1.007$ & 0.327 & 1.002 & $0.999-1.006$ & 0.255 \\
\hline WHV (BSA-indexed), $\mathrm{cm}^{3} / \mathrm{m}^{2}$ & 1.006 & $0.996-1.015$ & 0.272 & 1.006 & $0.997-1.015$ & 0.184 \\
\hline WHV (BSA-indexed + $\ln$-transformed) & 10.91 & $0.25-468.10$ & 0.213 & 13.02 & $0.41-415.72$ & 0.146 \\
\hline \multicolumn{7}{|c|}{ Non-obstructive CAD: $1-69 \%$ stenosis $(N=2268$; MACE: $N=76)$} \\
\hline WHV (absolute) $\mathrm{cm}^{3}$ & 0.997 & $0.995-0.999$ & 0.003 & 0.997 & $0.996-0.999$ & 0.001 \\
\hline WHV (BSA-indexed), $\mathrm{cm}^{3} / \mathrm{m}^{2}$ & 0.992 & $0.988-0.997$ & 0.002 & 0.993 & $0.989-0.997$ & 0.002 \\
\hline WHV (BSA-indexed + ln-transformed) & 0.064 & $0.013-0.317$ & 0.001 & 0.060 & $0.013-0.269$ & $<0.001$ \\
\hline \multicolumn{7}{|c|}{ Obstructive CAD: $\geq 70 \%$ stenosis $(N=233$; MACE: $N=29)$} \\
\hline WHV (absolute), $\mathrm{cm}^{3}$ & 0.999 & $0.997-1.002$ & 0.671 & 1.000 & $0.998-1.003$ & 0.899 \\
\hline WHV (BSA-indexed), $\mathrm{cm}^{3} / \mathrm{m}^{2}$ & 0.998 & $0.991-1.005$ & 0.623 & 0.999 & $0.993-1.006$ & 0.803 \\
\hline WHV (BSA-indexed $+\ln$-transformed) & 0.55 & $0.04-7.01$ & 0.648 & 0.80 & $0.08-8.14$ & 0.853 \\
\hline
\end{tabular}

Association of WHV with MACE (death, MI, or hospitalization for unstable angina) was driven by those with non-obstructive CAD. ASCVD, atherosclerotic cardiovascular disease; $B S A$, body surface area; $C A D$, coronary artery disease; $\ln$, natural log; $M A C E$, major adverse cardiac events; $W H V$, whole heart volume 
Fig. 4 Quintiles of WHV and MACE in non-obstructive CAD. Significantly reduced event-free survival in patients with WHV in the first quintile (Q1) as compared to Q2-5 (log-rank results displayed as Q1 vs. Q2-5). All KM-curves were adjusted for ASCVD and Leaman score. $Q 1-$ Q5= quintiles of WHV. KaplanMeier curves for WHV in no- and obstructive CAD did not show significant results and are shown in Supplemental Figure S1
Non-obstructive CAD $(\mathrm{N}=\mathbf{2 , 2 6 8 )}$

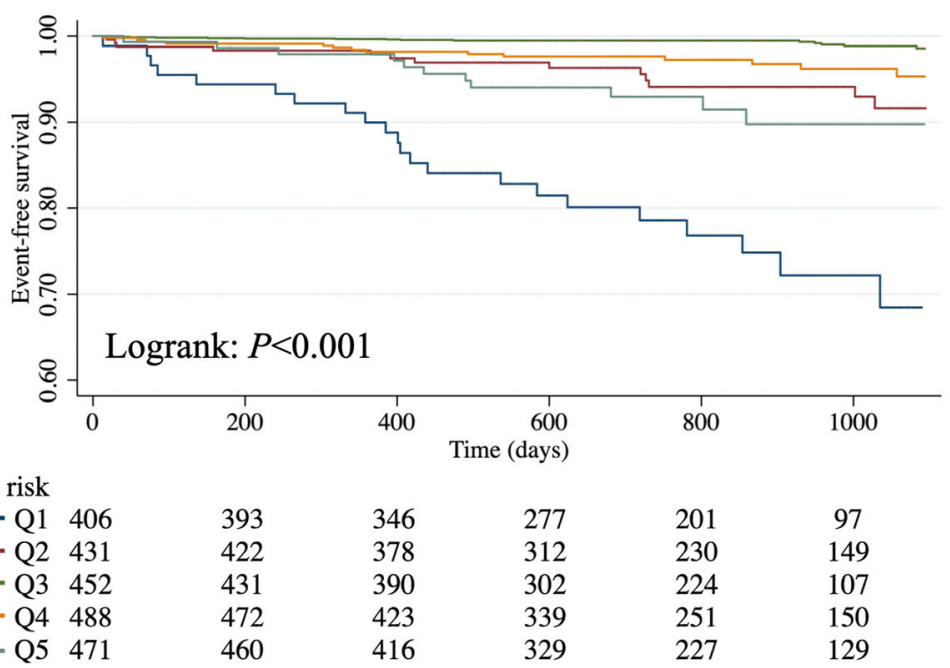

MACE [27, 29]. PROMISE patients with small WHV had normal cardiac function based on prior definitions [30], including those with MACE.

Moreover, coronary microvascular dysfunction (CMD) and HFpEF are closely related, and a recent study found that $70-80 \%$ of patients with HFpEF also have CMD [31]. CMD and HFpEF also share clinical risk factors such as hypertension, diabetes, smoking, obesity, and chronic inflammatory disorders $[32,33]$, the majority of risk factors found in those with small WHV in our study. Our results add to the growing body of evidence, suggesting that CMD may be associated with non-obstructive CAD [32-35] and, thus, may represent a potential link between non-obstructive CAD and HFpEF.

Given that PROMISE did not include patients with heart failure or known CAD (i.e., groups with often enlarged hearts), we hypothesize that the association between small WHV and MACE may represent the left segment of a J- shaped relationship between WHV and MACE. This phenomenon has been described for other markers of $\mathrm{CV}$ risk, such as obesity [36]. However, this suggestion is hypothesisgenerating and requires further investigation.

\section{Large hearts and MACE}

In our cohort, patients with more advanced $\mathrm{CAD}$ on cardiac CT (e.g., elevated CAC or Leaman score, obstructive CAD, or HRPF present) or, in general, elevated CV risk (i.e., ASCVD risk score $\geq 7.5 \%$ ) presented with larger hearts. As expected, patients with larger hearts presented with rather typical $\mathrm{CV}$ events, such as CV death or non-fatal myocardial infarction. To some degree, these findings corroborate well-known associations of pathologically enlarged hearts, for example, those with clinical heart failure, dilatated or ischemic cardiomyopathy, and MACE $[9,14,37-41]$. It is crucial to understand that the PROMISE trial excluded patients with clinical signs of

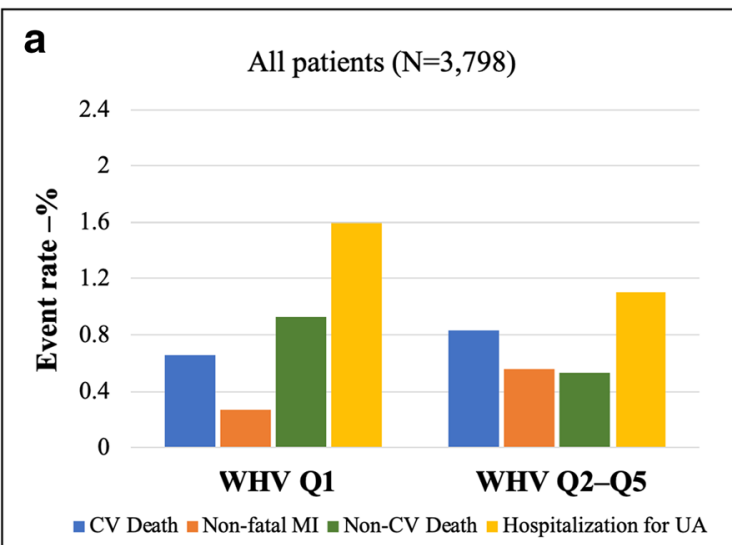

Fig. 5 Event types and WHV. Patients with small WHV (Q1) presented with rather unspecific event types while those with higher WHV presented more frequently with specific cardiovascular events, an observation

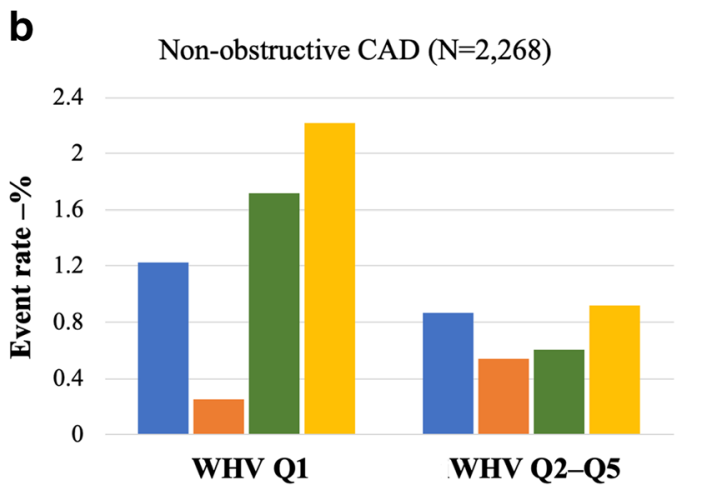

$₫ \mathrm{CV}$ Death $₫$ Non-fatal MI $₫$ Non-CV Death $₫$ Hospitalization for UA

particularly seen in non-obstructive $\mathrm{CAD}$. CAD, coronary artery disease; $\mathrm{CV}$, cardiovascular; MI, myocardial infarction; Q1-Q5, quintiles of WHV; UA, unstable angina; WHV, whole heart volume 
Fig. 6 Incremental value of WHV in non-obstructive CAD. Addition of WHV to clinical risk factors and CT-derived CAD characteristics increased the discriminatory capacity significantly by $4.6 \%$. Addition of WHV to the model resulted in a statistically significant improvement of model fit $\left(X^{2}=17.9 ; p<0.001\right)$. AUC, area under the receiver operator characteristic curve; ASCVD, atherosclerotic cardiovascular disease; WHV, body surface areaindexed whole heart volume. To maintain readability, only curves for the composites are displayed here. Individual curves are available in Supplemental Figure S2

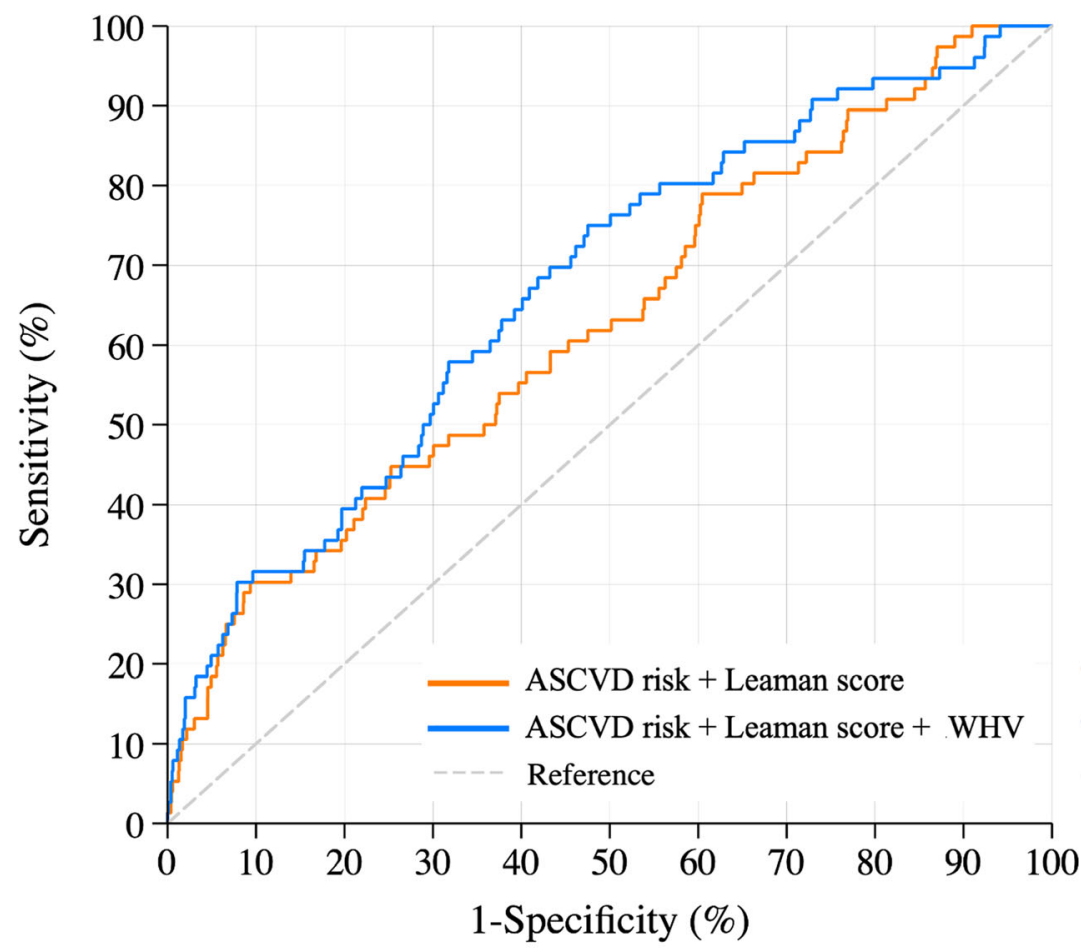

\begin{tabular}{|c|c|c|}
\hline Parameter & AUC & 95\% CI \\
\hline ASCVD risk score & 0.627 & $0.561-0.692$ \\
\hline Leaman score & 0.599 & $0.530-0.667$ \\
\hline WHV & 0.589 & $0.521-0.656$ \\
\hline ASCVD risk + Leaman score & 0.627 & $0.560-0.693$ \\
\hline ASCVD risk + Leaman score + WHV & 0.673 & $0.610-0.735$ \\
\hline
\end{tabular}

heart failure or known $\mathrm{CAD}$, an aspect of selection that may explain why there was not a clear association between large hearts and MACE in our cohort.

\section{Future perspectives}

Future studies adding markers of structural and functional alterations of the heart (e.g., myocardial stiffness, interstitial collagen content, diastolic dysfunction, and strain), as well as CMD measures, are needed to test our hypothesis that small WHV relates to CMD and HFpEF in non-obstructive CAD. Moreover, studies of WHV in community-based populations, including those with enlarged hearts/heart failure, are needed to investigate the J-shaped relationship between WHV and MACE.

\section{Clinical relevance}

Our group and others have shown that non-obstructive CAD is related to an increased risk of MACE [3, 4]. In the PROMISE trial, non-obstructive CAD was associated with a threefold increased risk for MACE compared to no $\mathrm{CAD}$ and accounted for the majority of events [3]. Thus, there is an unmet need for further risk stratification. Our study delivers a novel imaging marker that may improve risk stratification in this cohort at increased CV risk.

\section{Limitations}

Our study is a retrospective secondary analysis of a large randomized trial. Accordingly, our results are hypothesisgenerating rather than confirmatory and need validation in large prospective cohorts. A comparison of WHV between patients with chest pain and normal WHV values was not possible since normal WHV has not been defined yet. Normal range of WHV will need to be derived from populations free of clinical symptoms. Despite the large scale of the PROMISE trial, the number of events is limited to provide reliable results in patient subgroups (e.g., quintiles of WHV in women and men with nonobstructive disease). 


\section{Conclusion}

In stable chest pain patients, smaller WHV is an independent prognostic marker of MACE. Particularly in patients with non-obstructive CAD, small WHV may help to stratify CV risk beyond the traditional $\mathrm{CV}$ risk factors and $\mathrm{CT}$ measures of $\mathrm{CAD}$ and may help to guide clinical management.

Acknowledgements Dr. Hoffmann received Research Grants from the National Institutes of Health (U01HL092040, U01HL092022), and Siemens Medical Solutions, Heart Flow Inc., and served as a consultant for Heart Flow. Dr. Lu reports consulting fees with PQBypass and a research grant from the Nvidia Corporation Academic Program. Dr. Lu is supported by grants from the American Heart Association Precision Medicine Institute 18UNPG34030172 and the Harvard University Center For AIDS Research NIH/NIAID 5P30AI060354-14. Dr. Ferencik reports receiving a grant from the American Heart Association 13FTF16450001. The other authors have nothing to disclose.

Funding The PROMISE trial was supported by grants from the National Heart, Lung, and Blood Institute (R01HL098237, R01HL098236, R01HL098305, and R01HL098235).

\section{Compliance with ethical standards}

Guarantor The scientific guarantor of this publication is Dr. Borek Foldyna.

Conflict of interest The authors of this manuscript declare no relationships with any companies whose products or services may be related to the subject matter of the article.

Statistics and biometry One of the authors (Prof. Thomas Mayrhofer) has significant statistical expertise and no complex statistical methods were necessary for this paper.

Informed consent Local and central institutional review boards approved the study, and all patients provided written informed consent.

Ethical approval Local and central institutional review boards approved the study.

Study subjects or cohorts overlap This investigation is a sub-study of the Prospective Multicenter Imaging Study for Evaluation of Chest Pain (PROMISE) trial.

\section{Methodology}

- Secondary analysis

- Multicenter randomized controlled trial

\section{References}

1. Knuuti J, Wijns W, Saraste A et al (2019) ESC Guidelines for the diagnosis and management of chronic coronary syndromes The Task Force for the diagnosis and management of chronic coronary syndromes of the European Society of Cardiology (ESC). Eur Heart J. https://doi.org/10.1093/eurheartj/ehz425

2. Emami H, Takx RAP, Mayrhofer T et al (2017) Non-obstructive CAD by coronary CTA improves risk stratification and allocation of statin therapy. JACC Cardiovasc Imaging 10:1031-1038. https:// doi.org/10.1016/j.jcmg.2016.10.022

3. Hoffmann U, Ferencik M, Udelson JE et al (2017) Prognostic value of noninvasive cardiovascular testing in patients with stable chest pain: insights from the PROMISE trial. Circulation. https://doi.org/ 10.1161/CIRCULATIONAHA.116.024360

4. Lin FY, Shaw LJ, Dunning AM et al (2011) Mortality risk in symptomatic patients with nonobstructive coronary artery disease: a prospective 2-center study of 2,583 patients undergoing 64-detector row coronary computed tomographic angiography. J Am Coll Cardiol 58:510-519. https://doi.org/10.1016/j.jacc.2010.11.078

5. Ferencik M, Mayrhofer T, Bittner DO et al (2018) Use of high-risk coronary atherosclerotic plaque detection for risk stratification of patients with stable chest pain: a secondary analysis of the PROMISE randomized clinical trial. JAMA Cardiol. https://doi. org/10.1001/jamacardio.2017.4973

6. Budoff MJ, Thomas M, Maros F et al (2017) Prognostic value of coronary artery calcium in the PROMISE study (Prospective Multicenter Imaging Study for Evaluation of Chest Pain). Circulation 136:1993-2005. https://doi.org/10.1161/ CIRCULATIONAHA.117.030578

7. Lu MT, Park J, Ghemigian K et al (2016) Epicardial and paracardial adipose tissue volume and attenuation - association with high-risk coronary plaque on computed tomographic angiography in the ROMICAT II trial. Atherosclerosis 251:47-54. https://doi.org/10. 1016/j.atherosclerosis.2016.05.033

8. Goeller M, Achenbach S, Marwan M et al (2018) Epicardial adipose tissue density and volume are related to subclinical atherosclerosis, inflammation and major adverse cardiac events in asymptomatic subjects. J Cardiovasc Comput Tomogr 12:67-73. https://doi. org/10.1016/j.jcct.2017.11.007

9. Kizer JR, Bella JN, Palmieri V et al (2006) Left atrial diameter as an independent predictor of first clinical cardiovascular events in middle-aged and elderly adults: the Strong Heart Study (SHS). Am Heart J 151:412-418

10. Bittencourt MS, Blankstein R, Mao S et al (2016) Left ventricular area on non-contrast cardiac computed tomography as a predictor of incident heart failure - The Multi-Ethnic Study of Atherosclerosis. J Cardiovasc Comput Tomogr 10:500-506. https://doi.org/10.1016/j. ject.2016.07.009

11. Dimopoulos K, Giannakoulas G, Bendayan I et al (2013) Cardiothoracic ratio from postero-anterior chest radiographs: a simple, reproducible and independent marker of disease severity and outcome in adults with congenital heart disease. Int J Cardiol 166: 453-457. https://doi.org/10.1016/j.ijcard.2011.10.125

12. Giamouzis G, Sui X, Love TE, Butler J, Young JB, Ahmed A (2008) A propensity-matched study of the association of cardiothoracic ratio with morbidity and mortality in chronic heart failure $\uparrow \uparrow$ The Digitalis Investigation Group (DIG) study was conducted and supported by the NHLBI in collaboration with the DIG investigators. This report was prepared using a limited-access data set obtained by the NHLBI and does not necessarily reflect the opinions or views of the DIG study or the NHLBI. Am J Cardiol 101:343-347. https://doi.org/10.1016/j.amjcard.2007.08.039

13. Hemingway H, Shipley M, Christie D, Marmot M (1998) Cardiothoracic ratio and relative heart volume as predictors of coronary heart disease mortality The Whitehall study 25 year followup. Eur Heart J 19:859-869. https://doi.org/10.1053/euhj.1997. 0862

14. Zaman MJS, Sanders J, Crook AM et al (2007) Cardiothoracic ratio within the "normal" range independently predicts mortality in patients undergoing coronary angiography. Heart 93:491-494. https:// doi.org/10.1136/hrt.2006.101238

15. Douglas PS, Hoffmann U, Lee KL et al (2014) PROspective multicenter imaging study for evaluation of chest pain: rationale and 
design of the PROMISE trial. Am Heart J 167:796-803.e1. https:// doi.org/10.1016/j.ahj.2014.03.003

16. Mosteller RD (1987) Simplified calculation of body-surface area. $\mathrm{N}$ Engl J Med 317:1098. https://doi.org/10.1056/ NEJM198710223171717

17. Welcome to Python.org. In: Python.org. https://www.python.org/. Accessed 2 Dec 2020

18. TensorFlow. In: TensorFlow. https://www.tensorflow.org/. Accessed 2 Dec 2020

19. Keras: the Python deep learning API. https://keras.io/. Accessed 2 Dec 2020

20. (2017) CUDA Zone. In: NVIDIA Dev. https://developer.nvidia. com/cuda-zone. Accessed 2 Dec 2020

21. 3D Slicer. https://www.slicer.org/. Accessed 2 Dec 2020

22. Agatston AS, Janowitz WR, Hildner FJ, Zusmer NR, Viamonte M Jr, Detrano R (1990) Quantification of coronary artery calcium using ultrafast computed tomography. J Am Coll Cardiol 15:827832

23. de Araújo Gonçalves P, Garcia-Garcia HM, Dores H et al (2013) Coronary computed tomography angiography-adapted Leaman score as a tool to noninvasively quantify total coronary atherosclerotic burden. Int J Cardiovasc Imaging 29:1575-1584. https://doi. org/10.1007/s10554-013-0232-8

24. Paulus WJ, Tschöpe C (2013) A novel paradigm for heart failure with preserved ejection fraction: comorbidities drive myocardial dysfunction and remodeling through coronary microvascular endothelial inflammation. J Am Coll Cardiol 62:263-271. https://doi. org/10.1016/j.jacc.2013.02.092

25. ter Maaten JM, Damman K, Verhaar MC et al (2016) Connecting heart failure with preserved ejection fraction and renal dysfunction: the role of endothelial dysfunction and inflammation. Eur J Heart Fail 18:588-598. https://doi.org/10.1002/ejhf.497

26. Kalogeropoulos A, Georgiopoulou V, Psaty BM et al (2010) Inflammatory markers and incident heart failure risk in older adults: the health $\mathrm{ABC}$ (Health, Aging, and Body Composition) Study. J Am Coll Cardiol 55:2129-2137. https://doi.org/10.1016/j.jacc. 2009.12.045

27. Velagaleti RS, Gona P, Pencina MJ et al (2014) Left ventricular hypertrophy patterns and incidence of heart failure with preserved versus reduced ejection fraction. Am J Cardiol 113:117-122. https://doi.org/10.1016/j.amjcard.2013.09.028

28. Shah RV, Abbasi SA, Heydari B et al (2013) Insulin resistance, subclinical left ventricular remodeling, and the obesity paradox: MESA (Multi-Ethnic Study of Atherosclerosis). J Am Coll Cardiol 61:1698-1706. https://doi.org/10.1016/j.jacc.2013.01.053

29. Pierdomenico SD, Lapenna D, Bucci A, Manente BM, Cuccurullo F, Mezzetti A (2004) Prognostic value of left ventricular concentric remodeling in uncomplicated mild hypertension. Am J Hypertens 17:1035-1039. https://doi.org/10.1016/j.amjhyper.2004.06.016

30. Fuchs A, Mejdahl MR, Kühl JT et al (2016) Normal values of left ventricular mass and cardiac chamber volumes assessed by 320 - detector computed tomography angiography in the Copenhagen General Population Study. Eur Heart J Cardiovasc Imaging 17: 1009-1017. https://doi.org/10.1093/ehjci/jev337

31. Shah SJ, Lam CSP, Svedlund S et al (2018) Prevalence and correlates of coronary microvascular dysfunction in heart failure with preserved ejection fraction: PROMIS-HFpEF. Eur Heart J 39: 3439-3450. https://doi.org/10.1093/eurheartj/ehy531

32. Camici PG, Crea F (2007) Coronary microvascular dysfunction. N Engl J Med 356:830-840. https://doi.org/10.1056/NEJMra061889

33. Tona F, Serra R, Di Ascenzo L et al (2014) Systemic inflammation is related to coronary microvascular dysfunction in obese patients without obstructive coronary disease. Nutr Metab Cardiovasc Dis 24:447-453. https://doi.org/10.1016/j.numecd.2013.09.021

34. Crea F, Bairey Merz CN, Beltrame JF et al (2017) The parallel tales of microvascular angina and heart failure with preserved ejection fraction: a paradigm shift. Eur Heart J 38:473-477. https://doi.org/ 10.1093/eurheartj/ehw461

35. Lee JF, Barrett-O'Keefe Z, Garten RS et al (2016) Evidence of microvascular dysfunction in heart failure with preserved ejection fraction. Heart 102:278-284. https://doi.org/10.1136/heartjnl2015-308403

36. Lavie CJ, McAuley PA, Church TS, Milani RV, Blair SN (2014) Obesity and cardiovascular diseases: implications regarding fitness, fatness, and severity in the obesity paradox. J Am Coll Cardiol 63: 1345-1354. https://doi.org/10.1016/j.jacc.2014.01.022

37. Moller JE, Hillis GS, Oh JK et al (2003) Left atrial volume: a powerful predictor of survival after acute myocardial infarction. Circulation 107:2207-2212

38. Vasan RS, Larson MG, Benjamin EJ, Evans JC, Levy D (1997) Left ventricular dilatation and the risk of congestive heart failure in people without myocardial infarction. N Engl J Med 336:1350 1355. https://doi.org/10.1056/NEJM199705083361903

39. Lauer MS, Evans JC, Levy D (1992) Prognostic implications of subclinical left ventricular dilatation and systolic dysfunction in men free of overt cardiovascular disease (the framingham heart study). Am J Cardiol 70:1180-1184. https://doi.org/10.1016/ 0002-9149(92)90052-Z

40. Raymond RJ, Hinderliter AL, Willis PW et al (2002) Echocardiographic predictors of adverse outcomes in primary pulmonary hypertension. J Am Coll Cardiol 39:1214-1219. https:// doi.org/10.1016/S0735-1097(02)01744-8

41. Sun JP, James KB, Sheng Yang X et al (1997) Comparison of mortality rates and progression of left ventricular dysfunction in patients with idiopathic dilated cardiomyopathy and dilated versus nondilated right ventricular cavities. Am J Cardiol 80:1583-1587. https://doi.org/10.1016/S0002-9149(97)00780-7

Publisher's note Springer Nature remains neutral with regard to jurisdictional claims in published maps and institutional affiliations. 